\title{
Article \\ Effectiveness of Epoxy Coating Modified with Yttrium Oxide Loaded with Imidazole on the Corrosion Protection of Steel
}

\author{
Muddasir Nawaz ${ }^{1}$, Nazal Naeem ${ }^{1}$, Ramazan Kahraman ${ }^{2, * \mathbb{D}}$, M. F. Montemor ${ }^{3} \mathbb{D}$, W. Haider ${ }^{1,4} \mathbb{D}$ \\ and R. A. Shakoor $1, *$ (D) \\ 1 Center for Advanced Materials (CAM), Qatar University, Doha 2713, Qatar; m.nawaz@qu.edu.qa (M.N.); \\ nazalnaeem14@gmail.com (N.N.); haide1w@cmich.edu (W.H.) \\ 2 Department of Chemical Engineering, Qatar University, Doha 2713, Qatar \\ 3 Centro de Química Estrutural, Departamento de Engenharia Química, Instituto Superior Técnico, \\ Universidade de Lisboa, Av Rovisco Pais, 1049-001 Lisboa, Portugal; mfmontemor@tecnico.ulisboa.pt \\ 4 Mechanical and Materials Engineering, Central Michigan University, Mount Pleasant, MI 48859, USA \\ * Correspondence: ramazank@qu.edu.qa (R.K.); shakoor@qu.edu.qa (R.A.S.); Tel.: +974-4403-4130 (R.K.); \\ +974-4403-6867 (R.A.S.)
}

check for updates

Citation: Nawaz, M.; Naeem, N.; Kahraman, R.; Montemor, M.F.; Haider, W.; Shakoor, R.A.

Effectiveness of Epoxy Coating Modified with Yttrium Oxide Loaded with Imidazole on the Corrosion Protection of Steel. Nanomaterials 2021, 11, 2291. https://doi.org/ 10.3390/nano11092291

Academic Editor: Maciej Sitarz

Received: 23 July 2021

Accepted: 30 August 2021

Published: 3 September 2021

Publisher's Note: MDPI stays neutral with regard to jurisdictional claims in published maps and institutional affiliations.

\begin{abstract}
The search for highly effective corrosion protection solutions to avoid degradation of the metallic parts is enabling the development of polymeric organic coatings. Of particular relevance, polymeric nanocomposite coatings, modified with corrosion inhibitors, have been developed to provide enhanced surface protection. In this work, yttrium oxide nanoparticles loaded with corrosion inhibitor (Imidazole), used as additives in the formulation of epoxy for coated on the steel substrate. The loading of $\mathrm{Y}_{2} \mathrm{O}_{3}$ with imidazole was confirmed by field emission scanning electron microscopy (FE-SEM) and Fourier transform infrared spectroscopy (FTIR), thermogravimetric analysis (TGA) and Brunauer-Emmett-Teller analysis. UV-Vis analysis demonstrated the $\mathrm{pH}$-sensitive behavior of the imidazole that helps in self-release when necessary. Electrochemical impedance spectroscopy (EIS) of the coated samples revealed that the coating modified with $\mathrm{Y}_{2} \mathrm{O}_{3} /$ IMD provides better corrosion protection compared to coatings containing only $\mathrm{Y}_{2} \mathrm{O}_{3}$. XPS analysis validated the presence of an imidazole protective film on the steel substrate that enhanced the corrosion resistance of the coated samples
\end{abstract}

Keywords: epoxy; yttrium oxide; imidazole; coating; corrosion protection

\section{Introduction}

Corrosion is a relevant degradation phenomenon in metallic components that affects many industries, leading to high economic burden and safety hazards. A very effective route to protect metallic assets from corrosion is by the application of protective organic coatings. In the last decades, there has been an increase in academic and industrial research in developing organic coatings containing anti-corrosive pigments for the protection of metallic parts in different environments [1,2]. Traditionally, coatings are modified with anti-corrosive pigments that release inhibiting species able to protect the metallic parts, contributing to a higher lifespan [3-5]. However, it is important to ensure that these pigments are environmentally compliant. For instance, chromate pigments have been intensively used for a very long time, but chromium (VI) possesses a carcinogenic and toxic nature. Its use has been strongly restricted or even prohibited [6,7]. Among the new non-toxic anticorrosive pigments introduced to substitute chromates, zinc phosphate has been widely accepted since its toxic level is reduced, and many studies have shown good its corrosion inhibition properties [8].

To enhance the corrosion protective efficiency of organic coatings for a longer lifespan, with a low impact on the environment, the use of nanotechnologies to develop carriers for loading active species has opened up a wide range of possibilities in the field $[9,10]$. The direct addition of corrosion inhibitors into coatings formulation may provide good efficiency 
but usually, this may lead to unwanted reactions and degradation of the coating matrix which causes early leaching of the inhibitors and decreases the barrier properties of the coating $[11,12]$. This drawback has been circumvented thanks to the use of carriers loaded with the inhibitors that also helps to enhance the barrier properties of the coating $[13,14]$. This strategy also helps to prevent unnecessary leaching of inhibitors and achieve more economical and efficient use of the corrosion inhibitors. Notably, the use of carriers requires specific triggers that shall promote the release of inhibitors under certain conditions such as $\mathrm{pH}$ change, light or mechanical damage [15]. Various types of carriers, loaded with different actives species, have been studied in recent years, such as metal oxides, layered double hydroxides and layer by layer assemblies based on polyelectrolytes [16,17]. Effective release of inhibitors has been achieved by developing shell-like capsules or porous matrices that are activated under certain conditions. Despite effectiveness, it has been reported that the release of corrosion inhibitors through shell-like capsules is controlled by permeation through the shell material. This may lead to capsules collapse and poor mechanical stability and faster release and early loss of inhibitors. To ensure a stable release of inhibitors when required and for a longer life without loss of mechanical stability, the use of porous inorganic carriers has been proposed as an alternative $[18,19]$.

Therefore, mesoporous oxide nanoparticles (e.g., silica, ceria, and zirconia) have been reported as suitable carriers to transport the corrosion inhibitors [20-22]. Yttrium oxide can also be used as a corrosion inhibitor carrier due to its porous character [23]. Yttrium oxide because of its high thermal, chemical, and mechanical stability and low toxicity in nature has been widely used for many applications, including those requiring high corrosion resistance [24]. Therefore, in this work, porous yttrium oxide is selected as carrier for the storage of a corrosion inhibitor.

The azole family, including thiazoles, triazoles and imidazole, has been proposed as corrosion inhibitors for copper, but has been scarcely explored to inhibit steel corrosion. Interestingly, imidazole can be loaded into $\mathrm{Y}_{2} \mathrm{O}_{3}$ and used as anti-corrosive pigments in protective epoxy coatings exposed to aggressive environment $[25,26]$. Thus, this work aims to investigate the effectiveness of the new anti-corrosive pigment based on yttrium oxide $\left(\mathrm{Y}_{2} \mathrm{O}_{3}\right)$ loaded with imidazole as a corrosion inhibitor when incorporated into the epoxy formulation for the coating of steel plates. The results revealed that $\mathrm{Y}_{2} \mathrm{O}_{3}$ loaded with imidazole improves the corrosion resistivity of the epoxy coated steel substrates by attaining $99 \%$ corrosion inhibition efficiency.

\section{Materials and Methods}

\subsection{Materials and Chemicals}

Yttrium oxide nanoparticles and imidazole as corrosion inhibitor were purchased from Sigma-Aldrich. Epoxy (EPON RESIN 815C) with (EPIKURE 3234) as its curing agent were purchased from Hexion chemicals. Plain carbon steel coupons were purchased from a local supplier with a composition of ( $\mathrm{Fe}=$ Balance, $\mathrm{C}=0.21 \%, \mathrm{Mn}=0.30 \%, \mathrm{Cu}=0.20 \%, \mathrm{~S}=0.04 \%$, $\mathrm{P}=0.04 \%$ ). The steel substrate was polished with emery papers from 80 to 320 grit size. After that, rinsed with distilled water and acetone and coupons $30 \times 30 \times 1.0 \mathrm{~mm}^{3}$ were used.

\subsection{Loading of Corrosion Inhibitor into $\mathrm{Y}_{2} \mathrm{O}_{3}$ Nanoparticles}

Yttrium oxide nanoparticles have a high surface area and are porous. Thus, $3.0 \mathrm{wt}$. \% of $\mathrm{Y}_{2} \mathrm{O}_{3}$ nanoparticles were soaked into $10 \mathrm{mg} / \mathrm{mL}$ IMD water solution and sonicated for $30 \mathrm{~min}$ at room temperature. After that, the solution was put on a hot plate at $70{ }^{\circ} \mathrm{C}$ for $24 \mathrm{~h}$ with moderate stirring. The dried loaded $\mathrm{Y}_{2} \mathrm{O}_{3}$ nanoparticles were obtained once the excess solvent removed. The Figure 1 presents the schematic diagram of loading of $\mathrm{Y}_{2} \mathrm{O}_{3}$ with imidazole. 

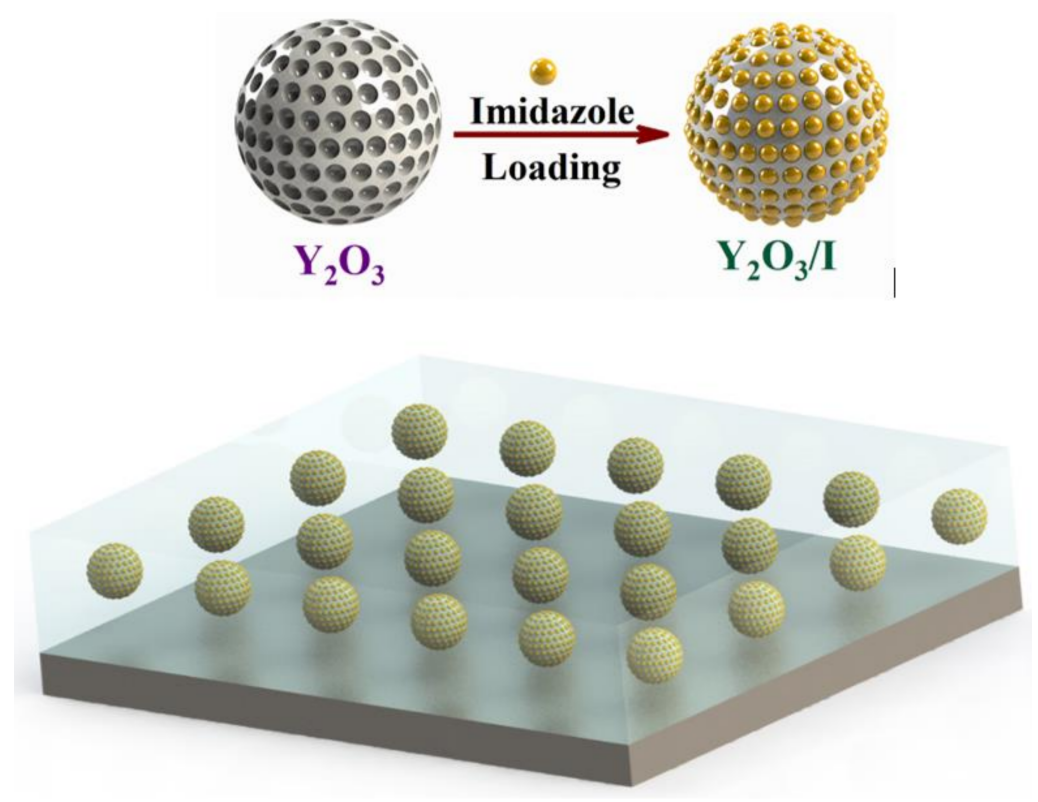

Figure 1. Schematic diagram showing the incorporation of $\mathrm{Y}_{2} \mathrm{O}_{3} / \mathrm{IMD}$ in the epoxy coating.

\subsection{Coating Formulation of Steel Substrate}

The $1 \mathrm{wt}$. \% of yttrium oxide loaded with imidazole $\left(\mathrm{Y}_{2} \mathrm{O}_{3} / \mathrm{IMD}\right)$ was added into the epoxy resin with the curing agent and ultrasonicated for the $10 \mathrm{~min}$ to obtain a homogeneous mixture. Epoxy was a low viscosity liquid bisphenol A based resin containing a commercial grade of n-butyl glycidyl ether and curing agent unmodified aliphatic amines, while the epoxy to curing agent ratio was kept 4:1. Doctor blade was used for coating on the steel coupons. The dried coating thickness of $100 \pm 5 \mu \mathrm{m}$ was obtained after a compete curing at room temperature for a week.

The adhesion strength of the epoxy coating was $6.4 \pm 2 \mathrm{MPa}$. The FE-SEM cross sectional image for thickness of coating shown in (Figure S1). Two types of coatings were formulated.

i. $\quad$ Reference coating (contained only $\mathrm{Y}_{2} \mathrm{O}_{3}$ );

ii. Modified coating (contained $\mathrm{Y}_{2} \mathrm{O}_{3} / \mathrm{IMD}$ ).

\subsection{Characterization of Nanoparticles and Coating Samples}

The phase purity of $\mathrm{Y}_{2} \mathrm{O}_{3}$ and loaded product $\left(\mathrm{Y}_{2} \mathrm{O}_{3} / \mathrm{IMD}\right)$ was investigated by $\mathrm{X}$-ray diffraction $(\mathrm{XRD})$ by using PAN analytical $\mathrm{X}^{\prime}$ pert Pro $\mathrm{Cu}(\mathrm{K} \alpha)$, with a scanning rate of $2^{\circ} /$ min and scanning angle ranging between $20^{\circ} \leq 2 \theta \leq 80^{\circ}$. The chemical composition and loading of $\mathrm{Y}_{2} \mathrm{O}_{3}$ nanoparticles were confirmed by FTIR analysis using the FT-IR Frontier (PerkinElmer, Frontier, Waltham, MA, USA) instrument. The spectra were recorded in the range of 4000 to $500 \mathrm{~cm}^{-1}$. The surface morphology of the $\mathrm{Y}_{2} \mathrm{O}_{3}$ and $\mathrm{Y}_{2} \mathrm{O}_{3} / \mathrm{IMD}$ was studied by a field emission scanning electron microscope (FE-SEM-Nova Nano-450, The Netherland) and transmission electron microscopy (TEM, FEI, TALOS F200X, New York, NY, USA). A TGA synchronization analyzer (PerkinElmer, TGA 4000, Boston, MA, USA) was used to analyze the thermal stability of the $\mathrm{Y}_{2} \mathrm{O}_{3}$ and $\mathrm{Y}_{2} \mathrm{O}_{3} / \mathrm{IMD}$ in the temperature range $30^{\circ} \mathrm{C}$ to $600{ }^{\circ} \mathrm{C}$ employing a heating rate of $10^{\circ} \mathrm{C} /$ minute. The surface charge of $\mathrm{Y}_{2} \mathrm{O}_{3}$ and $\mathrm{Y}_{2} \mathrm{O}_{3} / \mathrm{IMD}$ was determined by employing Zeta potential equipment (Malvern, Zeta sizer, Nano ZSP, Worcestershire, UK). The Brunauer-Emmett -Teller (BET) analysis was carried out by AimSizer (AS-3012) equipment to investigate the specific surface area and pore volume of $\mathrm{Y}_{2} \mathrm{O}_{3}$. The self-release behavior of the loaded product $\left(\mathrm{Y}_{2} \mathrm{O}_{3} / \mathrm{IMD}\right)$ was studied by UV-Vis spectroscopy analysis (LAMBDA 650 UV-Vis Spectrophotometer, PerkinElmer, Waltham, MA, USA). The presence of corrosion inhibitor on the surface of steel substrate was further analyzed by XPS (AXIX Ultra DLD, Kratos, UK) using a monochromatic $\mathrm{X}$-ray source- $\mathrm{Al} \mathrm{K} \alpha$ source; the reference binding energy of $\mathrm{C} 1 \mathrm{~s}$ was 
(284.6 eV). XPS wide spectra were recorded in the binding energy range of 250 to $750 \mathrm{eV}$ to determine the elemental composition. High-resolution spectra were recorded at an energy step size of $0.1 \mathrm{eV}$ using a pass energy of $10 \mathrm{eV}$.

The coating thickness of the coated samples was measured with a gauge meter (PosiTector 6000) and also by FE-SEM observation of the cross section. The adhesion strength of the coated was determined by peel-off test conducted by way of precision adhesion testing equipment (PAT AT101E/6.3 kN, Made in Norway).

The corrosion resistance of the coated samples was studied by electrochemical impedance spectroscopy (EIS) by using a three-electrode electrochemical cell in the $3.5 \mathrm{wt} . \% \mathrm{NaCl}$ solution. Coated steel sample as working electrode, graphite as counter working electrode and $\mathrm{Ag} / \mathrm{AgCl}$ as a reference electrode, respectively. The Gamry 3000 (30 K BOOSTER potentiostat/Galvanstate/ZRA, Warminster, PA, USA) was used for EIS analysis within a frequency range of $100 \mathrm{kHz}$ to $10 \mathrm{mHz}$, which starts from the higher to the lower limit. The EIS was measured at (OCP) for $1 \mathrm{~h}$ and the RMS signal was $10 \mathrm{mV}$.

\section{Results and Discussion}

\subsection{Structural and Morphological Characterization}

The morphological analysis of $\mathrm{Y}_{2} \mathrm{O}_{3}$ and $\mathrm{Y}_{2} \mathrm{O}_{3} /$ IMD was investigated FE-SEM and transmission electron microscopy (TEM) and the results are presented in Figure 2. Figure 2a,b evidence a nano textured irregular morphology, with some $\mathrm{Y}_{2} \mathrm{O}_{3}$ particles' agglomerates that are preserved after loading with the corrosion inhibitor. The size of the particles varies from few tens of $\mathrm{nm}$ up to $200 \mathrm{~nm}$ for the larger agglomerates. The TEM images shown in Figure 2c indicates that $\mathrm{Y}_{2} \mathrm{O}_{3}$ nanoparticles have some porosity, and its average size is below $50 \mathrm{~nm}$. The darker areas evidenced in Figure $2 \mathrm{~d}$ suggests the loading of $\mathrm{Y}_{2} \mathrm{O}_{3}$ with imidazole. This evidence was also supported by EDS analysis depicted in (Figure S2a,b) that show the presence of yttrium at $2 \mathrm{keV}$. The peaks at $0.15 \mathrm{KeV}$ and $0.27 \mathrm{KeV}$ correspond to $\mathrm{C}$ and $\mathrm{N}$, respectively. The increase in carbon intensity and the presence of nitrogen confirms the loading of imidazole into the porous $\mathrm{Y}_{2} \mathrm{O}_{3}$ nanoparticles.

The surface charge of the particles was measured by Zeta potential to confirm the loading of imidazole. The mean values of Zeta potential for $\mathrm{Y}_{2} \mathrm{O}_{3}$ are $12.9 \mathrm{mV}$ and $-47.89 \mathrm{mV}$ for imidazole presented in Figure S3. The opposite charges of $\mathrm{Y}_{2} \mathrm{O}_{3}$ and imidazole help on the loading process. The mean zeta potential of loaded product $\mathrm{Y}_{2} \mathrm{O}_{3} / \mathrm{IMD}$ is $2.24 \mathrm{mV}$ which is lower than the value determined for $\mathrm{Y}_{2} \mathrm{O}_{3}$. This also suggests that IMD is present in the porous structure of $\mathrm{Y}_{2} \mathrm{O}_{3}$.

The XRD pattern of $\mathrm{Y}_{2} \mathrm{O}_{3}$ and $\mathrm{Y}_{2} \mathrm{O}_{3} / \mathrm{IMD}$ are shown in Figure $3 \mathrm{a}$ and evidence the particles nature is crystalline. The distinct peaks at $29.11^{\circ}, 33.81^{\circ}, 48.45^{\circ}$ and $57.61^{\circ}$ could be attributed to crystal planes 111, 200, 220, 311 respectively, which is in accordance with JCPDS No: 98-018-5295 of $\mathrm{Y}_{2} \mathrm{O}_{3}$ crystal [23]. No significant differences are observed in the XRD pattern of $\mathrm{Y}_{2} \mathrm{O}_{3}$ and $\mathrm{Y}_{2} \mathrm{O}_{3} / \mathrm{IMD}$, and the lack of any extra peak(s) shows no relevant structural or phase changes occurs in the $\mathrm{Y}_{2} \mathrm{O}_{3}$ due to the presence of imidazole.

FTIR spectra of yttrium oxide nanoparticles, IMD and imidazole loaded yttrium oxide nanoparticles are presented in Figure 3b. A strong and sharp peak around $565 \mathrm{~cm}^{-1}$ is due to the characteristic of $\mathrm{Y}-\mathrm{O}$ vibration [27]. The characteristic bands of the two spectra by comparative analysis indicates that loaded $\mathrm{Y}_{2} \mathrm{O}_{3}$ nanoparticles are allied with the stretching vibrations of $\mathrm{C}-\mathrm{H}$ at around $3126 \mathrm{~cm}^{-1}, 3040 \mathrm{~cm}^{-1}$ and $2922 \mathrm{~cm}^{-1}$ [28]. As compared to the $\mathrm{Y}_{2} \mathrm{O}_{3}$, the spectra for the loaded $\mathrm{Y}_{2} \mathrm{O}_{3}$ nanoparticles showed the $\mathrm{N}-\mathrm{H}$ deformation band at around $755.5 \mathrm{~cm}^{-1}$ and the C-H bending was observed around $1050 \mathrm{~cm}^{-1}$ and $939.6 \mathrm{~cm}^{-1}$. The presence of a band at $755 \mathrm{~cm}^{-1}$ and $1000 \mathrm{~cm}^{-1}$ can be assigned to the $\mathrm{NH}_{2}$ bending and $\mathrm{C}-\mathrm{H}$ bending, respectively, as per literature [29]. According to the spectra for loaded nanoparticles, the appearance of two new bands at about $1323 \mathrm{~cm}^{-1}, 1255 \mathrm{~cm}^{-1}$ corresponds to medium-weak C-N stretching in Imidazole [30]. The absorption bands observed at $1506 \mathrm{~cm}^{-1}$ and $1456.2 \mathrm{~cm}^{-1}$ correspond to the $\mathrm{C}=\mathrm{C}$ spectrum and evidence the presence of imidazole into the porous $\mathrm{Y}_{2} \mathrm{O}_{3}$ nanoparticles. 


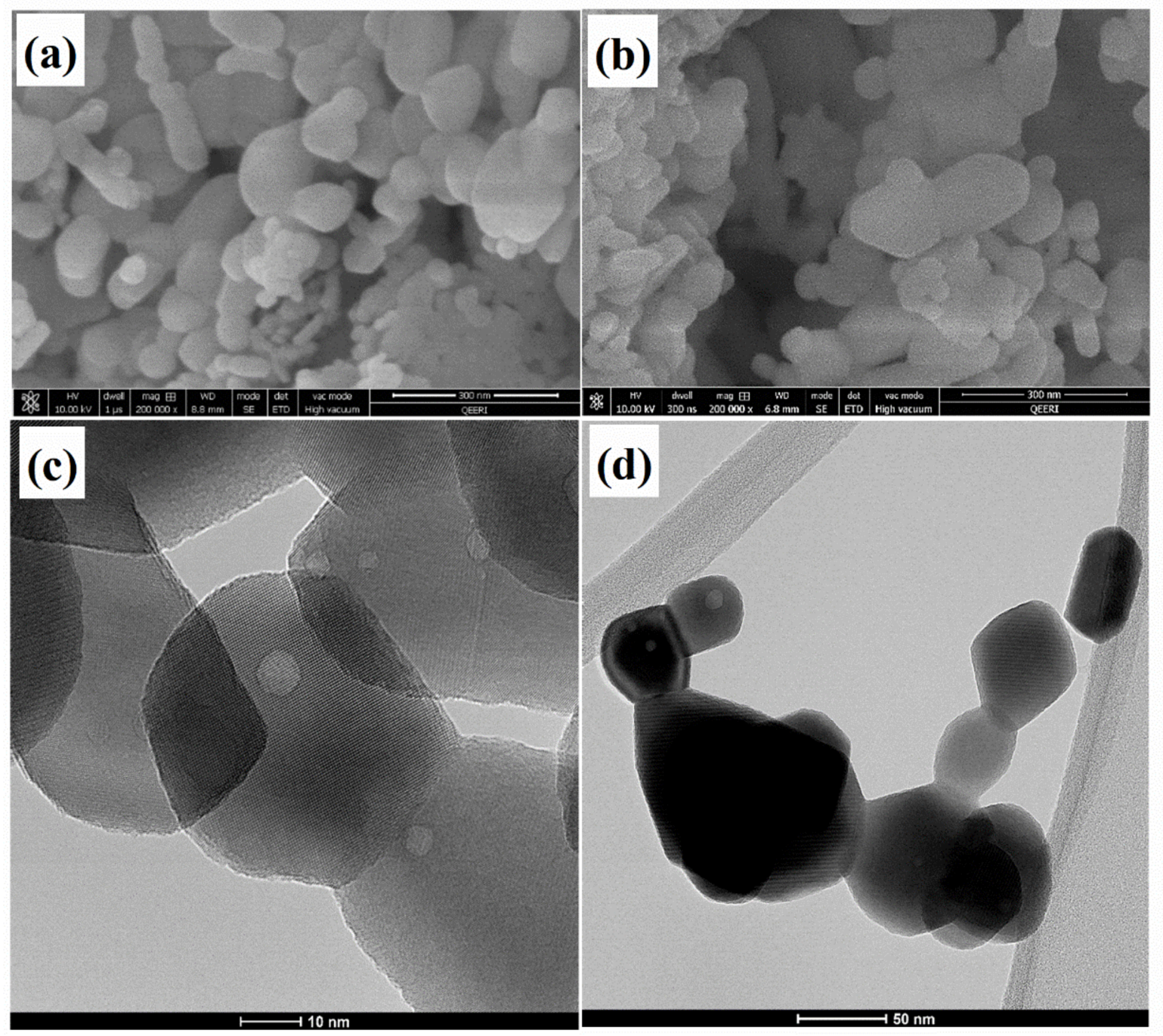

Figure 2. (a,b) FE-SEM, (c,d) TEM images of $\mathrm{Y}_{2} \mathrm{O}_{3}$ and $\mathrm{Y}_{2} \mathrm{O}_{3} /$ IMD.
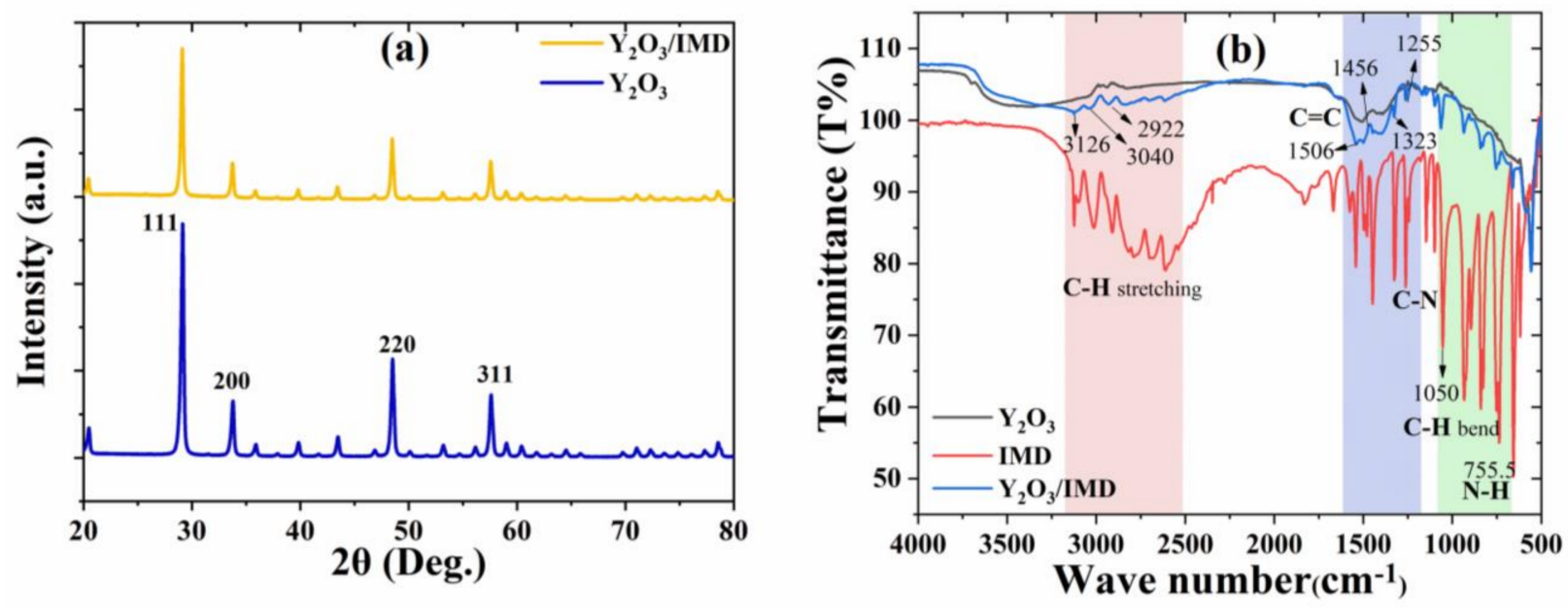

Figure 3. (a) XRD and (b) FTIR analysis of $\mathrm{Y}_{2} \mathrm{O}_{3}$ and $\mathrm{Y}_{2} \mathrm{O}_{3} /$ IMD. 


\section{Additional Physico-Chemical Characterization}

Thermal stability of pristine and loaded yttrium oxide nanoparticles was assessed by TGA. The $1 \mathrm{wt}$ \% weight loss of $\mathrm{Y}_{2} \mathrm{O}_{3}$ nanoparticles is due to removal of absorbed water molecules [27], as shown in Figure 4a. In contrast, weight loss of $\mathrm{Y}_{2} \mathrm{O}_{3} / \mathrm{IMD}$ observed in three stages of TGA spectra. In the first stage, a sharp weight loss occurs from room temperature $\left(28^{\circ} \mathrm{C}\right)$ to $200{ }^{\circ} \mathrm{C}$, due to the imidazole decomposition [31]. In the second stage $\left(201{ }^{\circ} \mathrm{C}\right.$ to $\left.400{ }^{\circ} \mathrm{C}\right)$, weight losses occur due to removing some residual compounds of imidazole until its complete decomposition. While considering that $256^{\circ} \mathrm{C}$ is the boiling point of imidazole. In the last stage, between $401^{\circ} \mathrm{C}$ to $600^{\circ} \mathrm{C}$, weight loss rate is constant. The pure yttrium oxide nanoparticles remain stable, and no significant weight loss observed. Hence, the weight loss in the case of loaded $\mathrm{Y}_{2} \mathrm{O}_{3}$ nanoparticles can be attributes to the removal of imidazole. It can be inferred from Figure $4 \mathrm{a}$, based on the quantity of the weight loss, approximately $5 \mathrm{wt}$. \% of imidazole were loaded into the porous yttrium oxide nanoparticles. The degradation peak for DTA around $150{ }^{\circ} \mathrm{C}$ is due to decomposition of imidazole.
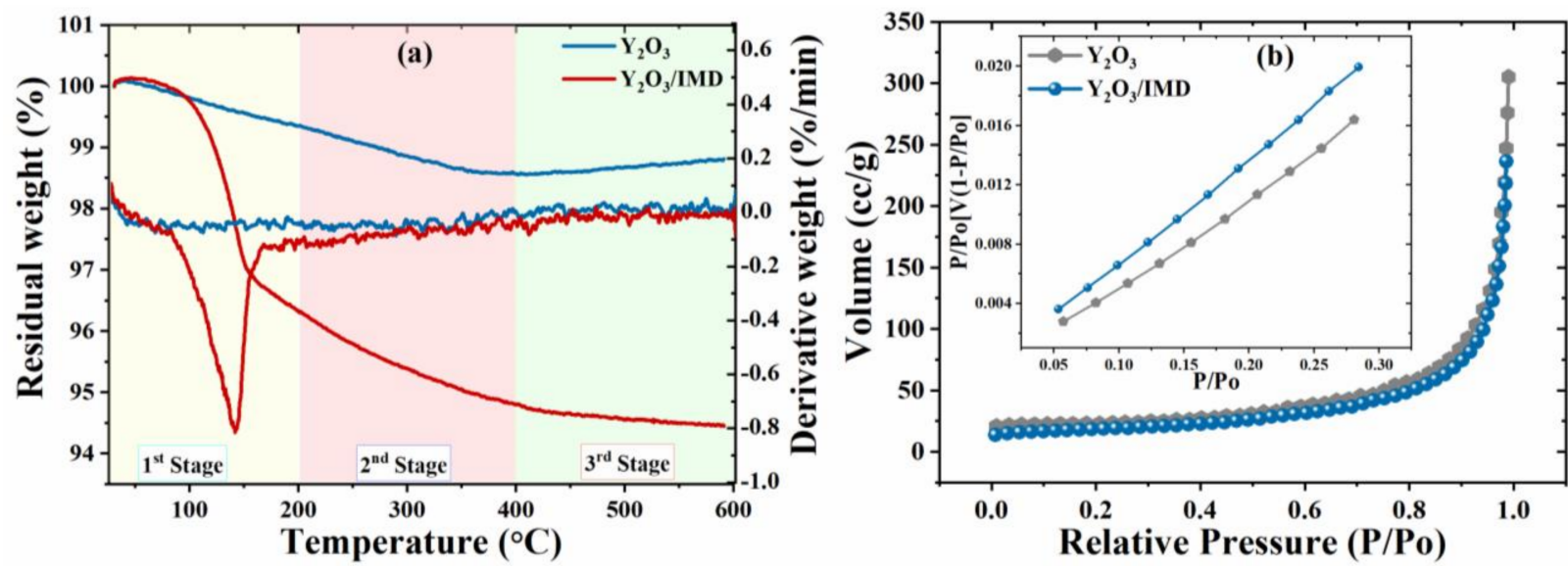

Figure 4. (a) TGA and DTA, (b) B.E.T analysis of $\mathrm{Y}_{2} \mathrm{O}_{3}$ and $\mathrm{Y}_{2} \mathrm{O}_{3}$ /imidazole.

The changes in the cumulative pore volume and specific surface area (SSA) for $\mathrm{Y}_{2} \mathrm{O}_{3}$ and $\mathrm{Y}_{2} \mathrm{O}_{3}$ /imidazole are observed by Brunauer-Emmett-Teller (B.E.T.) analysis-Figure $4 \mathrm{~b}$. The SSA value for $\mathrm{Y}_{2} \mathrm{O}_{3}$ is $73.729 \mathrm{~m}^{2} \mathrm{~g}^{-1}$ before loading, but it is reduced to $62.671 \mathrm{~m}^{2} \mathrm{~g}^{-1}$ after loading with imidazole. Similar to SSA, the cumulative pore volume reduced from $0.4744 \mathrm{ccg}^{-1}$ to $0.3675 \mathrm{ccg}^{-1}$ after loading. The reduction in SSA and cumulative pore volume confirms the loading of imidazole into $\mathrm{Y}_{2} \mathrm{O}_{3}$.

The UV-Vis spectroscopy analysis evidences the self-release behavior of the imidazole. Thus, $3.5 \mathrm{wt} . \%$ of $\mathrm{NaCl}$ solutions at different $\mathrm{pH}$ values $(2,7$ and 9$)$ were prepared and the loaded product $\left(\mathrm{Y}_{2} \mathrm{O}_{3}\right.$ /imidazole $)$ was dispersed in it. The UV-Vis spectra of $\mathrm{Y}_{2} \mathrm{O}_{3}$ /imidazole were taken after five days of immersion and presented in Figure 5. The UV spectra profiles are identical at different $\mathrm{pH}$ values, and a sharp peak at wavelength of $206 \mathrm{~nm}$ can be assigned to the aromatic structure of imidazole [28]. Absorbance peaks can be observed for all $\mathrm{pH}$ values (2, 7 and 11). The UV spectra at $\mathrm{pH} 2$ is presented in Figure 5a. The absorbance intensity of $3.5 \mathrm{AU}$ was measured at first day of immersion which slightly increases up to $~ 3.9 \mathrm{AU}$ and remains constant till Day 5 . The absorbance intensity at the first day of immersion is $1.5 \mathrm{AU}$ for $\mathrm{pH} 7$-Figure $5 \mathrm{~b}$ and increases up to 3.0 AU for the second day and 3.8 AU for the third day. The intensity decreases to 3.0 AU at the fifth day of immersion. The UV spectra taken at $\mathrm{pH} 11$ is presented in Figure $5 \mathrm{c}$ and its absorbance intensity increases from 3.0 AU (Day 1) to $4.0 \mathrm{AU}$ (Day 2). After that the intensity decreases to $3.3 \mathrm{AU}$ after three to four days and then increases to $4.0 \mathrm{AU}$ after the fifth day of immersion. A comparative trend with respect to immersion times at different $\mathrm{pH}$ values $(2,7$ and 11$)$ is presented in Figure $5 \mathrm{~d}$. The presence of inhibitor is confirmed in 
all different $\mathrm{pH}$ conditions (acidic, neutral, and basic) but it shows increased absorbance intensity in acidic medium as compared to basic and neutral [31].
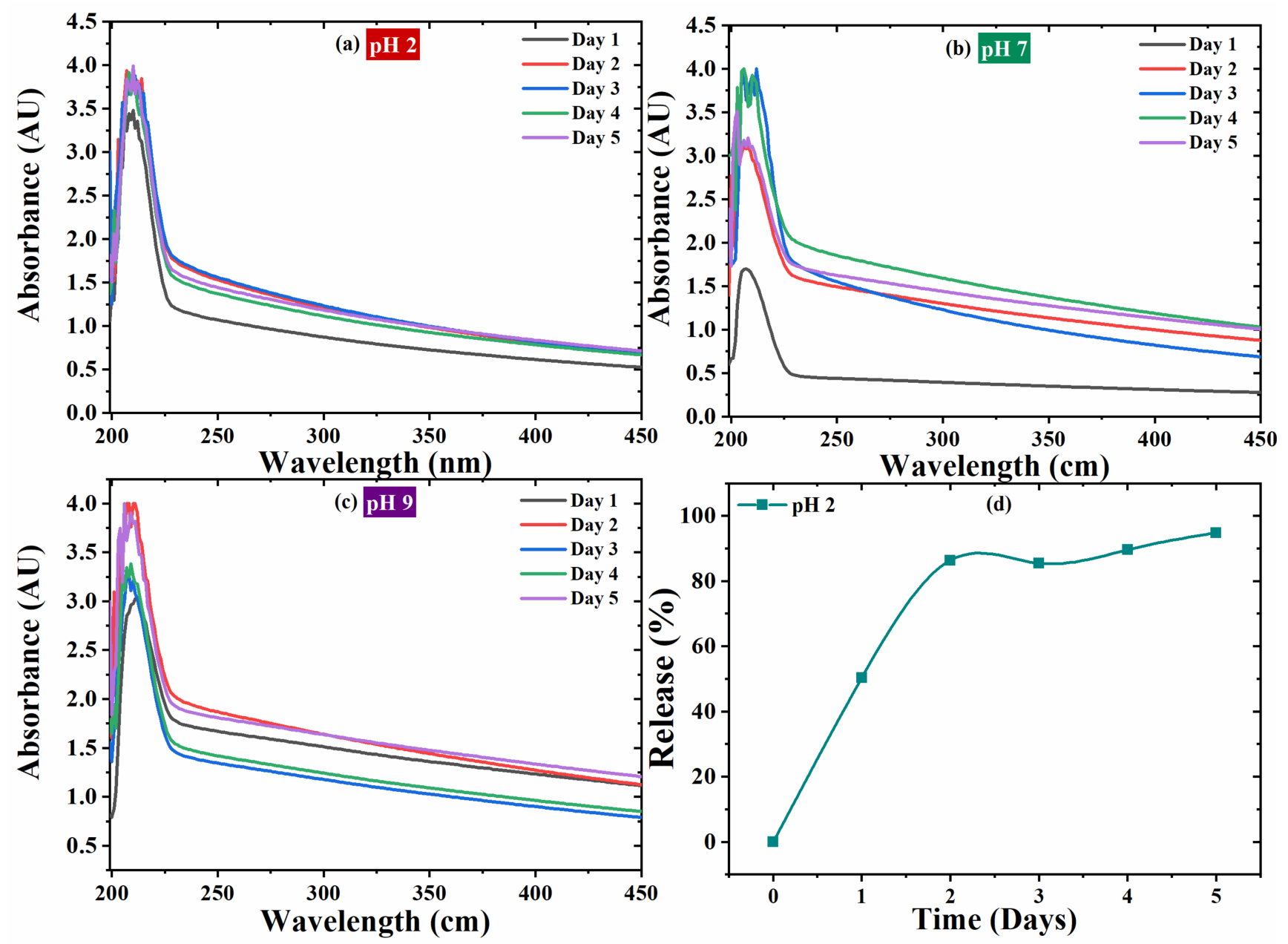

Figure 5. UV-Vis Spectra at (a) pH 2, (b) 7 and (c) 9 for $\mathrm{Y}_{2} \mathrm{O}_{3}$ /imidazole, (d) release (\%) plot.

The standard solution curve equation (Supplementary Figure S4) was used to evaluate the release percentage of imidazole from the $\mathrm{Y}_{2} \mathrm{O}_{3}$ and depicted in Figure 6. The release percentage (\%) of the corrosion inhibitor from the nano particles was calculated from Equation (1).

$$
\text { Release }(\%)=\mathrm{M}_{\mathrm{t}} / \mathrm{M}_{\mathrm{o}} \times 100
$$

where $\mathrm{M}_{\mathrm{t}}$ is the amount of inhibitor released with time obtained in different $\mathrm{pH}$ with UV-Vis spectroscopy and IMD standard curve and $\mathrm{M}_{\mathrm{O}}$ is the loaded amount from IMD into $\mathrm{Y}_{2} \mathrm{O}_{3}$ determined from TGA results. 

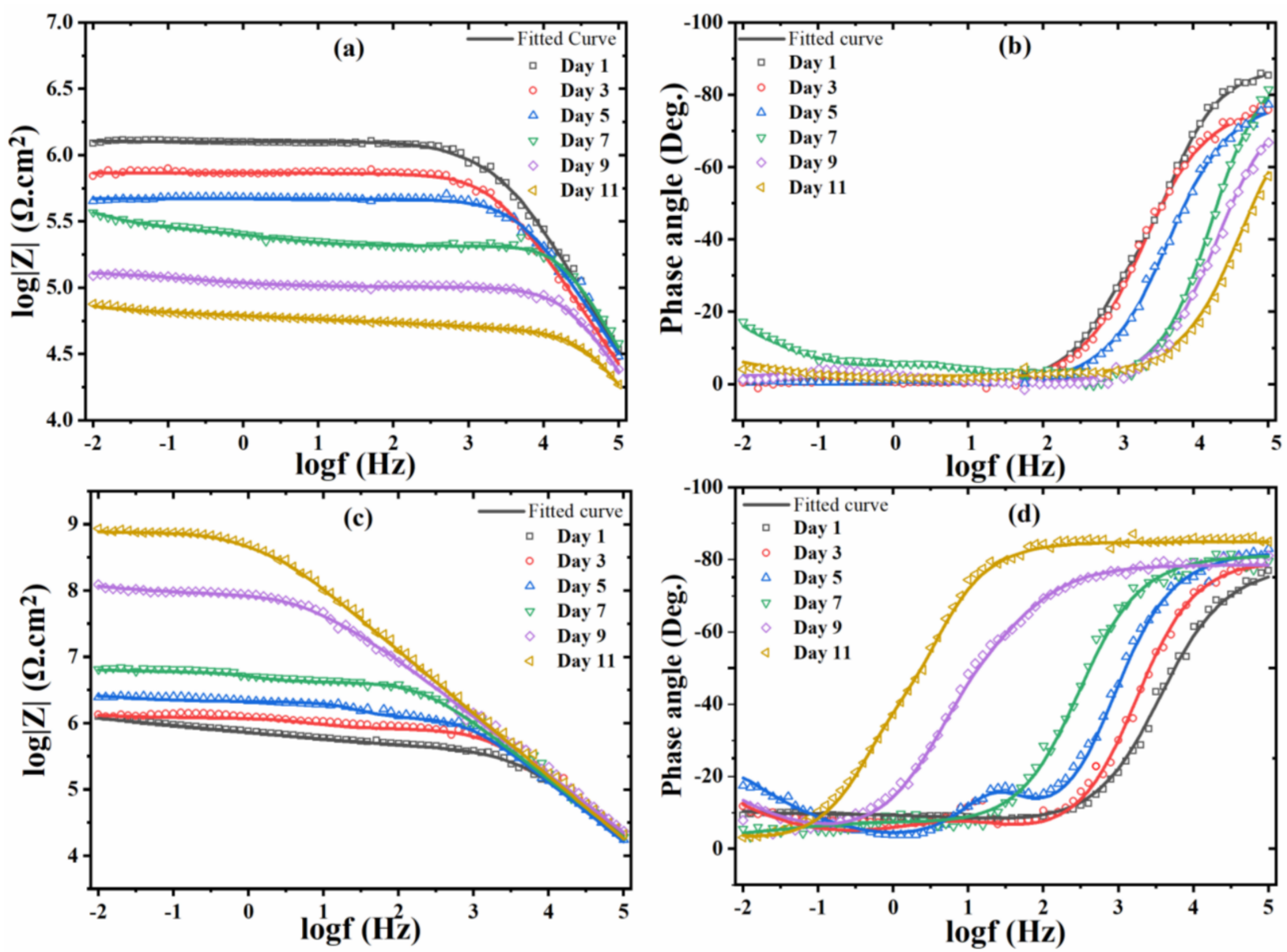

Figure 6. EIS Bode plots of $(\mathbf{a}, \mathbf{b})$ reference coating and (c,d) $\mathrm{Y}_{2} \mathrm{O}_{3} /$ IMD modified coating.

\subsection{Corrosion Resistance of Coated Steel Samples}

\subsubsection{Electrochemical Impedance Spectroscopy (EIS)}

The corrosion resistance of the coated samples was analyzed by electrochemical impedance spectroscopy (EIS) while immersed in $\mathrm{NaCl}$ solution. To accelerate corrosion a defect, made with a scalpel, was created in all coated samples. The Bode plots for the reference (only $\mathrm{Y}_{2} \mathrm{O}_{3}$ ) and modified $\left(\mathrm{Y}_{2} \mathrm{O}_{3} / \mathrm{IMD}\right.$ ) coatings are shown in Figure 6 and goodness of fit value presented in (Supplementary Table S1). The EIS spectra obtained for the reference coating shows a decrease in the overall impedance values over time, due to the corrosion propagation and electrolyte uptake from the defect made in the coating. The attenuation of the capacitive response in the region of high frequency indicates an increase of the active surface area, and therefore, delamination of the coating [32]. The impedance values for reference coating decrease more than one order of magnitude after 11 days of immersion.

The impedance spectra of the $\mathrm{Y}_{2} \mathrm{O}_{3}$ /IMD modified coating show an inverse trendFigure 6. Initially, the impedance values slightly increase with time. After seven days, the impedance values increased by one order of magnitude and from the seventh to the eleventh days, impedance values increased by two orders of magnitude. The initial increase was slower because as the electrolyte reached the steel substrate, corrosion is likely to start, inducing local $\mathrm{pH}$ changes that help to release the corrosion inhibitor. The inhibitor is expected to form a protective layer where the steel surface is exposed [33] that decreases the active surface area, delaying coating delamination and, therefore, increasing impedance values. The increase in impedance for the modified coating is followed by broadening of the high frequency time constant and development of a well-defined capacitive behavior in the 
region of high frequency [34]. This trend shows that the corrosion activity in and around the surface defect was inhibited and that the area of exposed steel was probably reduced.

The low-frequency impedance values for the modified coating increases over time as depicted in Figure 7a. While Nyquist plots for reference and modified coating presented in the Supplementary Data (Figure S6).
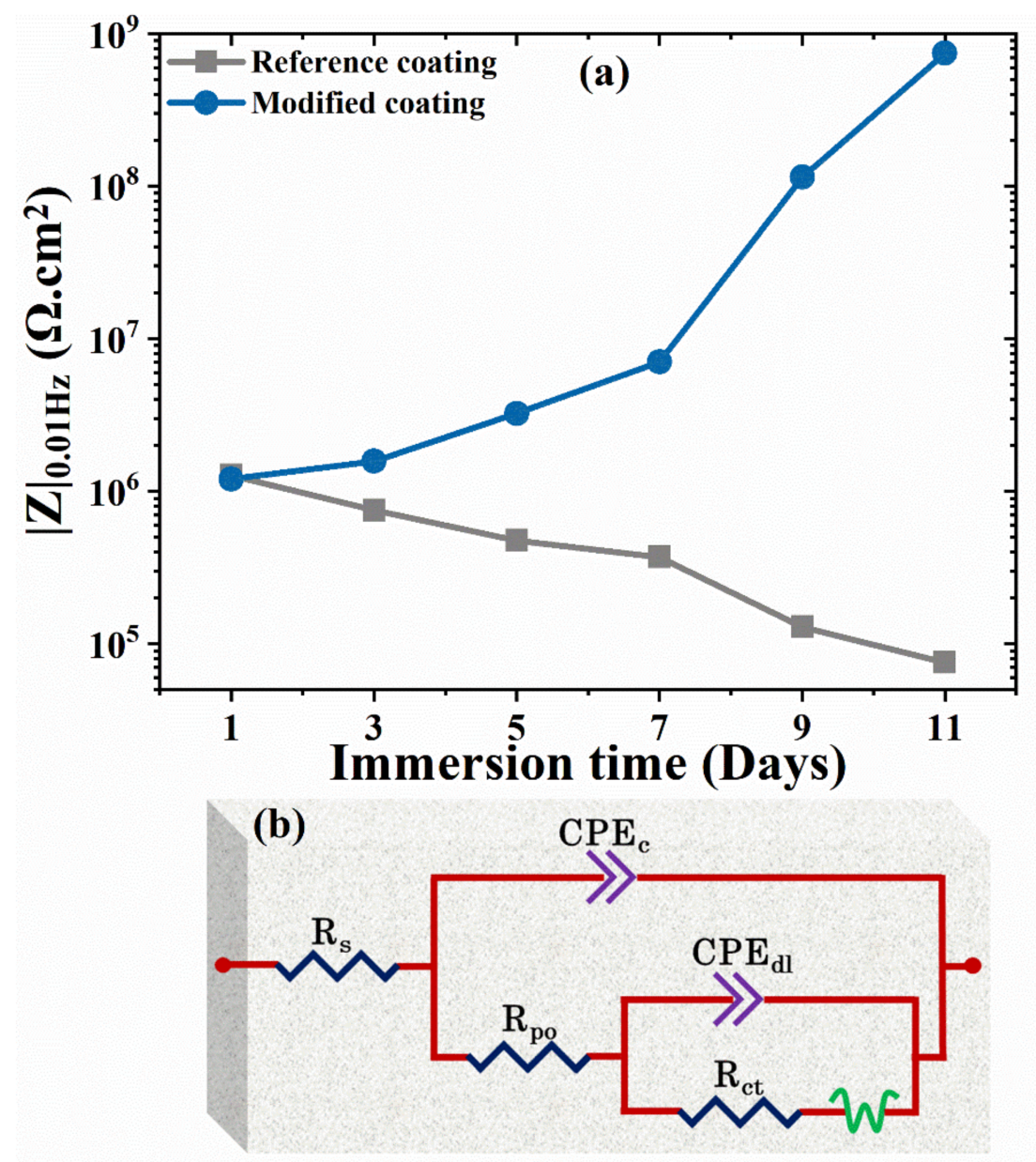

Figure 7. (a) Low impedance values for reference and modified coating; (b) equivalent circuit.

The values of relevant EIS parameters, namely solution resistance inside pores and scratch $\left(\mathrm{R}_{\mathrm{po}}\right)$, faradic resistance $\left(\mathrm{R}_{\mathrm{ct}}\right)$, and respective constant phase elements $\left(\mathrm{CPE}_{\mathrm{c}}, \mathrm{CPE} \mathrm{El}_{\mathrm{dl}}\right)$ were obtained after fitting with the equivalent circuit provided in Figure $7 \mathrm{~b}$ and Table S1. The high frequency capacitive slope corresponds to the coated areas and its constant phase element, while the low frequency time constant, $\mathrm{R}_{\mathrm{ct}}$ and $\mathrm{CPE}_{\mathrm{dl}}$, can be assigned to the surface activity in the scratched areas and bottom of the pores. The EIS fitting values are depicted in Figure 8. 

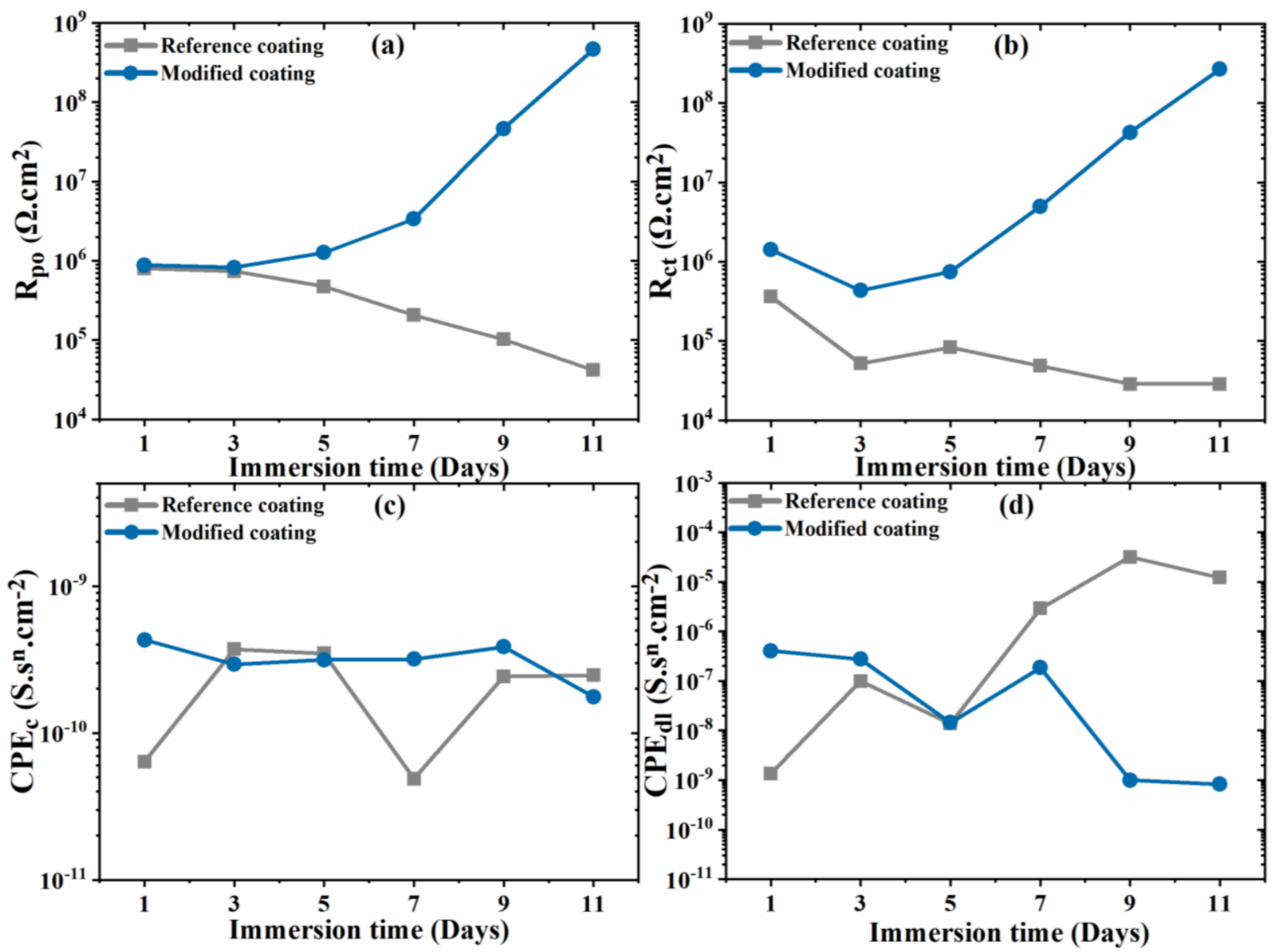

Figure 8. (a) Evolution of the pore resistance $\left(R_{p o}\right)$, (b) Faradic resistance $\left(R_{c t}\right)$, (c) admittance of coating $\left(C P E_{c}\right)$, (d) admittance of the double layer $\left(\mathrm{CPE}_{\mathrm{dl}}\right)$.

The high frequency resistance $\left(R_{\text {po }}\right)$ of the reference coating decreases from $\sim 1 \mathrm{M} \Omega . \mathrm{cm}^{2}$ to $41.79 \mathrm{~K} \Omega . \mathrm{cm}^{2}$ after immersion of 11 days-Figure $8 \mathrm{a}$-are due to continuous propagation of the delaminated area from the defect originally formed in the coating. The inhibited coating successfully resists to the progress of delamination probably due to development of a protective layer on the exposed surface of steel which decreases the fraction of metal exposed to the electrolyte [35] and inhibits the corrosion activity attenuating local $\mathrm{pH}$ changes, namely alkalization, which is the main responsible for cathodic delamination.

The evolution of the faradic resistance $\left(R_{c t}\right)$ with time-Figure $8 \mathrm{~b}$ shows a decrease for the reference coating, for more than one order of magnitude, evidencing that corrosion activity is increasing. Contrarily, for the for the inhibited coating $\left(\mathrm{Y}_{2} \mathrm{O}_{3} / \mathrm{IMD}\right)$ the faradic resistance increased by more than two orders of magnitude, suggesting that the surface activity is hindered in the presence of the particles loaded with the inhibitor.

The CPE values for both coatings are depicted in Figure $8 c, d$. The high frequency CPE for the reference coating tends to increase revealing increased electrolyte uptake in the coated areas while for the inhibited coating the values are nearly constant, suggesting that the coated parts remain more resistive. The low-frequency admittance values of the constant phase element for the reference coating increases for more than two orders of magnitude with time, probably due to a larger active surface area and progress of coating delamination from the scratch. However, for the inhibited coating, the values tend to be constant/slightly decreasing suggesting that the active surface area decreases, and that delamination was hindered and protecting the bare steel [36]. 
The impedance values for the reference $\left(\mathrm{Y}_{2} \mathrm{O}_{3}\right)$ and inhibited coatings $\left(\mathrm{Y}_{2} \mathrm{O}_{3} / \mathrm{IMD}\right)$ at different immersion times were used to calculate the inhibition efficiency (I.E \%) [31] Table 1.

$$
\text { I.E }(\%)=\left(1-R_{c t} / R_{c t 1}\right) \times 100
$$

where $\mathrm{R}_{\mathrm{ct}}$ is the faradic resistance value without inhibitor and $\mathrm{R}_{\mathrm{ct} 1}$ is for inhibited coating $\left(\mathrm{Y}_{2} \mathrm{O}_{3} / \mathrm{IMD}\right)$.

Table 1. Faradic resistance and corrosion inhibition efficiency of reference and $\mathrm{Y}_{2} \mathrm{O}_{3} / \mathrm{IMD}$ - modified coatings with change in immersion time.

\begin{tabular}{cccc}
\hline \multirow{2}{*}{ Immersion Time (Days) } & \multicolumn{3}{c}{ Faradic Resistance $\mathbf{( R}_{\mathbf{c t}}\left(\mathbf{\Omega . c m}^{\mathbf{2}}\right)$} \\
\cline { 2 - 4 } & Reference Coating & Modified Coating & I.E (\%) \\
\hline 1 & $3.630 \pm 0.7 \times 105$ & $1.411 \pm 0.6 \times 106$ & - \\
\hline 3 & $5.211 \pm 0.7 \times 104$ & $4.344 \pm 0.4 \times 105$ & 16.5 \\
\hline 5 & $8.311 \pm 1.2 \times 104$ & $7.475 \pm 1.4 \times 105$ & 51.4 \\
\hline 7 & $4.855 \pm 1.5 \times 104$ & $4.966 \pm 1.1 \times 106$ & 92.6 \\
\hline 9 & $2.859 \pm 0.2 \times 104$ & $4.264 \pm 0.3 \times 107$ & 99.1 \\
\hline 11 & $2.856 \pm 0.1 \times 104$ & $2.678 \pm 0.2 \times 108$ & 99.8 \\
\hline
\end{tabular}

\subsubsection{XPS Analysis}

The EIS results confirms the enhanced protective effect of the modified coating which may be due to formation of a stable protective layer on the metal surface. Thus, it is also important to verify if the adsorption of imidazole on the steel substrate forms a protective film. The coating was removed, and the steel substrate surface was studied by X-ray photoelectron spectroscopy (XPS) to investigate the presence of a protective film. The high resolution XPS spectra for C1s depicted in Figure 9a shows three different peaks. The broad and asymmetric tail towards high binding energy is due the $\mathrm{sp}^{2}$ hybridization present in imidazole. The binding energy peak at $284.4 \mathrm{eV}$ and 285.3 corresponds to the $\mathrm{C}-\mathrm{C}$ and $\mathrm{C}-\mathrm{H}$ bonding between the epoxy because some epoxy residues might remain on the steel substrate [37]. The peak at $286.4 \mathrm{eV}$ corresponds to carbon and oxygen containing species [38]. The HR-XPS spectra for O 1s can be decomposed into three peaks-Figure 9b. The binding energy at $529.2 \mathrm{eV}$ corresponds to the formation of oxides (likely Fe oxides). The peak at $530.9 \mathrm{eV}$ is due to the presence of $\mathrm{C}-\mathrm{O}$ bonds, the peak at $532.6 \mathrm{eV}$ corresponds to the presence of hydroxyl species, probably hydrated Fe compounds, [39,40]. The Fe $2 \mathrm{p}^{3 / 2}$ XPS spectra depicted in Figure $9 \mathrm{c}$, reveals a peak at $706.5 \mathrm{eV}$ that can be assigned to the metallic iron. The peaks at $710.3 \mathrm{eV}$ and $712.4 \mathrm{eV}$ corresponds to the Fe (II) and Fe (III) species, probably oxides and hydroxides which can also be observed in XPS spectra for $\mathrm{O} 1 \mathrm{~s}$ [41]. The $\mathrm{N}$ 1s XPS spectra shown in Figure 9d shows the two peaks. The peak at $\sim 398.6 \mathrm{eV}$ corresponds to the nitrogen species bounded to iron to form a linkage of $\mathrm{FeN}_{\mathrm{x}}$ [42]. The N1s spectra favors the adsorption of nitrogen on steel surface confirmed by the binding energy peak of $\mathrm{FeN}_{\mathrm{x}}$, which are consistent with previous study where mostly metal nitride forms in this energy band range [43]. While there is a peak at $400 \mathrm{eV}$, which is due to the bonding of $\mathrm{N}-\mathrm{CH}_{2}$. The XPS elemental atomic percentage chemical composition of the surface is provided in the Table 2. The presence of nitrogen confirms the adsorption of imidazole on the steel substrate. 

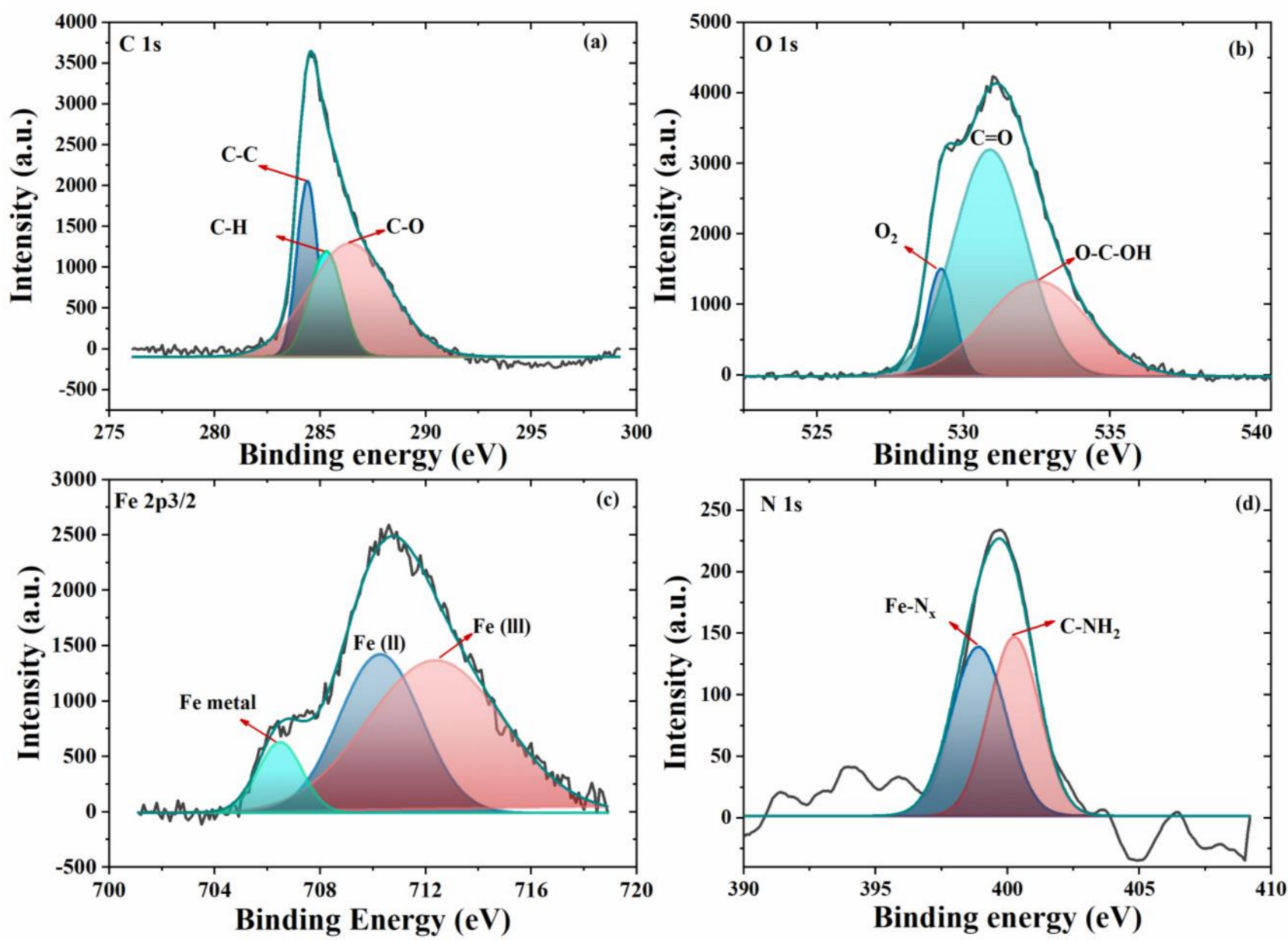

Figure 9. XPS analysis of surface after coating removal, High resolution spectra of (a) C 1s, (b) O 1s, (c) Fe $2 p^{3 / 2}$, (d) N 1s.

Table 2. Surface elemental composition of surface of XPS data.

\begin{tabular}{ccccc}
\hline \multirow{2}{*}{ Sample } & \multicolumn{4}{c}{ Surface Chemical Composition, Atomic \% } \\
\cline { 2 - 5 } & $\mathbf{C}$ & O & N & Fe \\
\hline Modified coating surface & 56.9 & 25.6 & 2.9 & 55.8 \\
\hline
\end{tabular}

The surface roughness of the surface after coating removal was measured by atomic force microscopy (AFM)-Figure 10b. Results seem to indicate that the steel surface of inhibited coating at the end of the EIS tests is relatively rough compared to the surface of reference coating. The surface roughness (R.M.S.) for the steel substrate of reference coating is R.M.S. $=9.542 \mathrm{~nm}$, that is increased to $15.937 \mathrm{~nm}$ in the presence of IMD (Figure 10). The increment in the surface roughness value can ascribed to the development of a thicker protective layer on the steel substrate surface in the presence of IMD. 

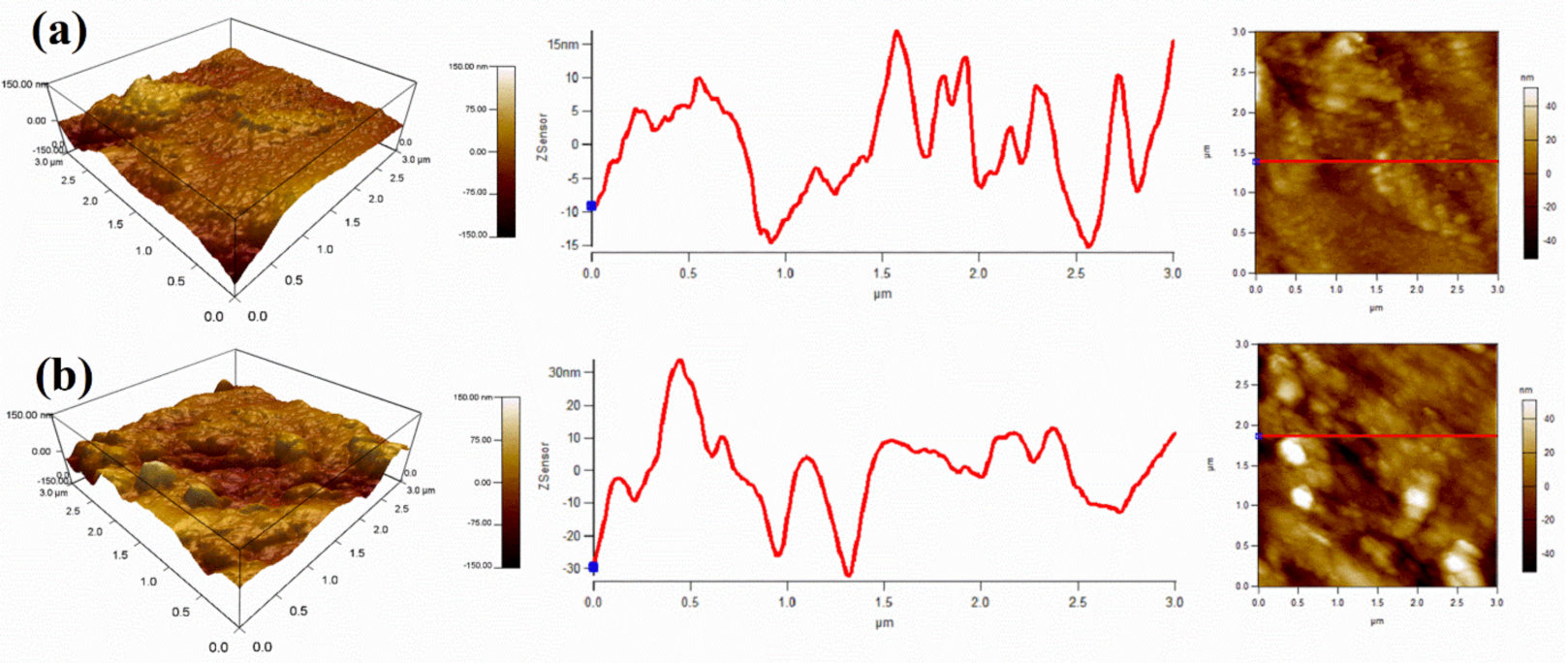

Figure 10. AFM analysis of (a) steel in absence of IMD, and (b) steel substrate in the presence of IMD.

\subsection{Corrosion Inhibition Mechanism}

The UV-Vis shows that loaded product $\left(\mathrm{Y}_{2} \mathrm{O}_{3} / \mathrm{IMD}\right)$ seems to be $\mathrm{pH}$ sensitive, a property that helps to release the inhibitor from the particles and improves corrosion inhibition as demonstrated by EIS. Initially when the electrolyte reaches steel the local $\mathrm{pH}$ changes due to corrosion activity [44]. The $\mathrm{pH}$ at the scratched area is expected to reach acidic values in the anodic areas due to $\mathrm{Fe}$ ions hydrolysis aiding on the release of the corrosion inhibitor. The inhibition effect observed for the $\mathrm{Y}_{2} \mathrm{O}_{3} / \mathrm{IMD}$-modified coating is due to the adsorption ability of imidazole on the steel substrate, according to the schematic diagram depicted in Figure 11.

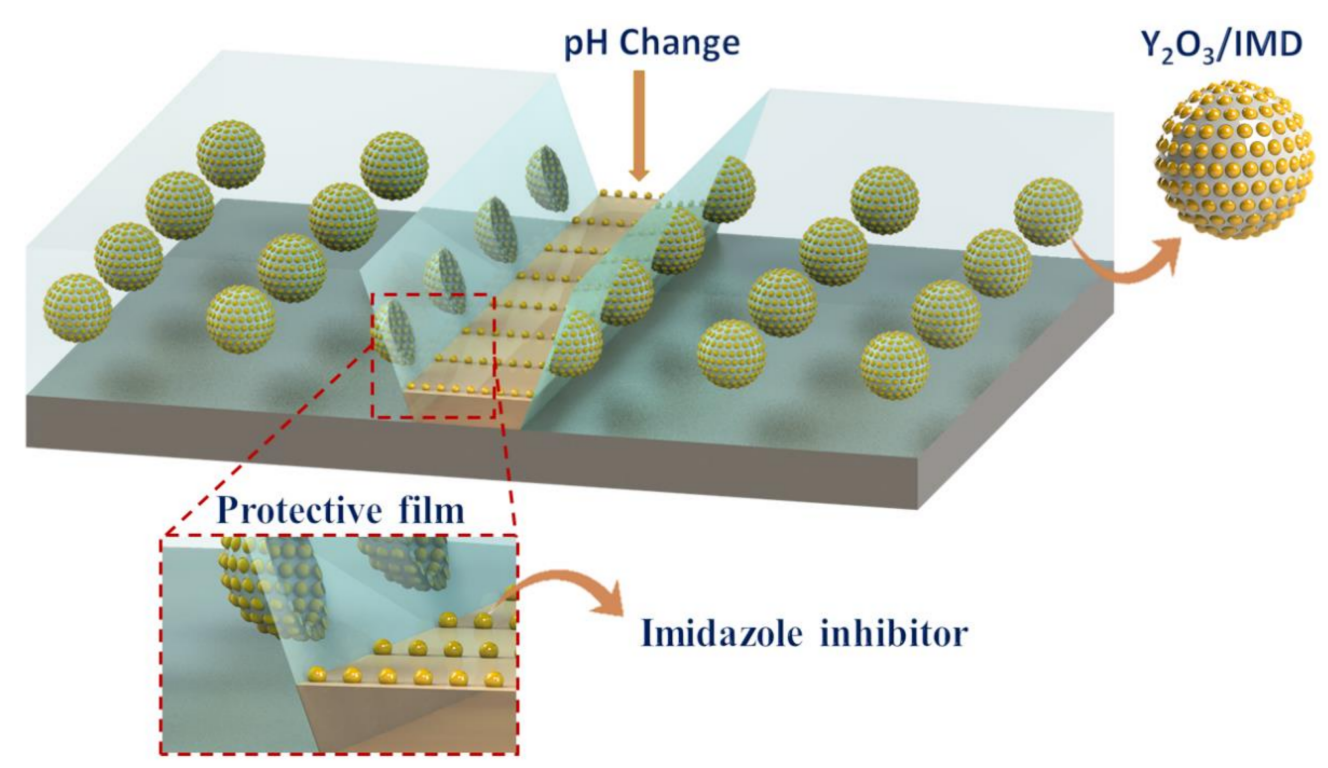

Figure 11. The schematic diagram explaining inhibition mechanism.

The inhibitor, which has been reported as a mixed-type-film forming corrosion inhibitor [45], is able to form a protective layer over steel slow downing corrosion activity. In fact, IMD shows three possible anchoring sites [46]: the nitrogen atom and the sp2 lone pair of electrons, the active hydrogen bon attached to the $\mathrm{N}$ atom and the $\pi$ bonds that are characteristic of the aromatic ring. The formation of a stable layer containing the inhibitor, which has been reported as hydrophobic, repeals water and aggressive species [47] and is responsible for the improved corrosion resistance. Possible reactions between the 
inhibitor and epoxy, contributing to higher coating resistance, can also be present and cannot be discarded [48,49]. Advanced modeling calculations [50] have shown that the stable inhibition performance of imidazole is due to the formation of a surface layer in which a cooperative effect between adsorption due to breaking of the double bonds in the aromatic rings and the formation of C-C sigma bonds between different molecules of the inhibitor. Interestingly, as the number of possible C-C sigma intermolecular bonds increases, the more stable and protective the surface film is. This "polymerization"-like effect is, therefore, responsible for the improved corrosion protection of the steel surface as demonstrated by EIS.

\section{Conclusions}

The anti-corrosive pigments $\mathrm{Y}_{2} \mathrm{O}_{3} /$ Imidazole were synthesized and dispersed in an epoxy formulation to prepare modified coatings for corrosion protection of steel substrates. The loading of imidazole into $\mathrm{Y}_{2} \mathrm{O}_{3}$ confirmed by FTIR, while TGA evidences the loading capacity of the $\mathrm{Y}_{2} \mathrm{O}_{3}$ nanoparticles. EIS studies reveal that the modified coating shows better anti-corrosive properties compared to the reference coating, probably due to a positive interaction between the inhibitor and the epoxy-based matrix. The EIS parameters show an increase of the corrosion activity in the non-inhibited coating and an important protection effect in the presence of the $\mathrm{Y}_{2} \mathrm{O}_{3}$ /imidazole modified coating. The imidazole release from the $\mathrm{Y}_{2} \mathrm{O}_{3}$ nanoparticles might be related to local changes in $\mathrm{pH}$ and formation of a stable and more protective layer over the exposed steel substrate. XPS analysis of the surface beneath the coating confirmed the presence of imidazole at the coating-metal interface at the end of the immersion tests in $\mathrm{NaCl}$.

Supplementary Materials: The following are available online at https: / www.mdpi.com/article / 10.3390/nano11092291/s1, Figure S1: Cross sectional image of dried coating thickness, Figure S2: EDS analysis of (a) $\mathrm{Y}_{2} \mathrm{O}_{3}$ and (b) $\mathrm{Y}_{2} \mathrm{O}_{3}$ /IMD, Figure S3: Zeta potential of $\mathrm{Y}_{2} \mathrm{O}_{3}$ and $\mathrm{Y}_{2} \mathrm{O}_{3}$ /Imidazole, Figure S4: (a) standard solution curve (b) Release percentage at pH 2, 7 and 9, Figure S5: Statistical distribution data of impedance value for (a) Reference (b) Modified coating, Figure S6: Nyquist plot (a) Reference and (b) Modified coatings, Table S1: EIS fitting parameters value for reference $\left(\mathrm{Y}_{2} \mathrm{O}_{3}\right)$ and modified coating $\left(\mathrm{Y}_{2} \mathrm{O}_{3} / \mathrm{IMD}\right)$.

Author Contributions: M.N.: Conceptualization, methodology, validation, formal analysis, investigation, writing —original draft N.N.: methodology, writing—original draft R.K.: resources, funding acquisition M.F.M.: validation, investigation, writing - review and editing, funding acquisition, W.H.: resources, R.A.S.: supervision, writing-review and editing, project administration, resources. All authors have read and agreed to the published version of the manuscript.

Funding: The research funding was provided by the Qatar National Research Fund (a member of the Qatar Foundation, Grant Number NPRP11S-1226-170132. The additional funding for the project was also provided under the project UIDB/00100/2020 and UIDP/00100/2020.

Data Availability Statement: The raw data required to reproduce these findings cannot be shared at this time as the data also forms part of an ongoing study.

Acknowledgments: This publication was made possible by NPRP11S-1226-170132 from the Qatar National Research Fund (a member of the Qatar Foundation). Statements made herein are solely the responsibility of the authors. The authors would like to thanks to the Central Laboratories Unit (CLU), Qatar University, 2713, Doha, Qatar for HR-TEM analysis. Authors from Portugal acknowledge FCT for the additional funding under the project UIDB/00100/2020 and UIDP/00100/2020.

Conflicts of Interest: The authors declare no conflict of interest.

\section{References}

1. Montemor, M.F. Functional and smart coatings for corrosion protection: A review of recent advances. Surf. Coat. Technol. 2014, 258, 17-37. [CrossRef]

2. Lyon, S.B.; Bingham, R.; Mills, D.J. Advances in corrosion protection by organic coatings: What we know and what we would like to know. Prog. Org. Coat. 2017, 102, 2-7. [CrossRef] 
3. Kartsonakis, I.A.; Athanasopoulou, E.; Snihirova, D.; Martins, B.; Koklioti, M.A.; Montemor, M.F.; Kordas, G.; Charitidis, C.A. Multifunctional epoxy coatings combining a mixture of traps and inhibitor loaded nanocontainers for corrosion protection of AA2024-T3. Corros. Sci. 2014, 85, 147-159. [CrossRef]

4. Nawaz, M.; Yusuf, N.; Habib, S.; Shakoor, R.A.; Ubaid, F.; Ahmad, Z.; Kahraman, R.; Mansour, S.; Gao, W. Development and properties of polymeric nanocomposite coatings. Polymers 2019, 11, 852. [CrossRef] [PubMed]

5. Nawaz, M.; Habib, S.; Khan, A.; Shakoor, R.A.; Kahraman, R. Cellulose microfibers (CMFs) as a smart carrier for autonomous self-healing in epoxy coatings. New J. Chem. 2020, 44, 5702-5710. [CrossRef]

6. Barnhart, J. Chromium chemistry and implications for environmental fate and toxicity. Soil Sediment Contam. 1997, 6, 561-568. [CrossRef]

7. Hughes, A.E.; Cole, I.S.; Muster, T.H.; Varley, R.J. Designing green, self-healing coatings for metal protection. NPG Asia Mater. 2010, 2, 143-151. [CrossRef]

8. Wan, H.; Song, D.; Li, X.; Zhang, D.; Gao, J.; Du, C. Effect of zinc phosphate on the corrosion behavior of waterborne acrylic coating/metal interface. Materials 2017, 10, 654. [CrossRef] [PubMed]

9. Montemor, M.F. Hybrid Nanocontainer-Based Smart Self-Healing Composite Coatings for the Protection of Metallic Assets; Elsevier: Amsterdam, The Netherlands, 2016; ISBN 9781782422839.

10. Morozov, Y.; Calado, L.M.; Shakoor, R.A.; Raj, R.; Kahraman, R.; Taryba, M.G.; Montemor, M.F. Epoxy coatings modified with a new cerium phosphate inhibitor for smart corrosion protection of steel. Corros. Sci. 2019, 159, 108128. [CrossRef]

11. Zheludkevich, M.L.; Shchukin, D.G.; Yasakau, K.A.; Möhwald, H.; Ferreira, M.G.S. Anticorrosion coatings with self-healing effect based on nanocontainers impregnated with corrosion inhibitor. Chem. Mater. 2007, 19, 402-411. [CrossRef]

12. Zea, C.; Barranco-García, R.; Alcántara, J.; Simancas, J.; Morcillo, M.; de la Fuente, D. pH-dependent release of environmentally friendly corrosion inhibitor from mesoporous silica nanoreservoirs. Microporous Mesoporous Mater. 2018, 255, 166-173. [CrossRef]

13. Raj, R.; Morozov, Y.; Calado, L.M.; Taryba, M.G.; Kahraman, R.; Shakoor, R.A.; Montemor, M.F. Calcium carbonate particles loaded with triethanolamine and polyethylenimine for enhanced corrosion protection of epoxy coated steel. Corros. Sci. 2020, 167, 108548. [CrossRef]

14. Ma, Y.; Zhang, Y.; Liu, J.; Ge, Y.; Yan, X.; Sun, Y.; Wu, J.; Zhang, P. GO-modified double-walled polyurea microcapsules/epoxy composites for marine anticorrosive self-healing coating. Mater. Des. 2020, 189, 108547. [CrossRef]

15. Wen, J.; Lei, J.; Chen, J.; Gou, J.; Li, Y.; Li, L. An intelligent coating based on pH-sensitive hybrid hydrogel for corrosion protection of mild steel. Chem. Eng. J. 2020, 392, 123742. [CrossRef]

16. Shchukin, D.G.; Zheludkevich, M.; Yasakau, K.; Lamaka, S.; Ferreira, M.G.S.; Möhwald, H. Layer-by-layer assembled nanocontainers for self-healing corrosion protection. Adv. Mater. 2006, 18, 1672-1678. [CrossRef]

17. Khan, A.; Ubaid, F.; Fayyad, E.M.; Ahmad, Z.; Shakoor, R.A.; Montemor, M.F.; Kahraman, R.; Mansour, S.; Hassan, M.K.; Hasan, A.; et al. Synthesis and properties of polyelectrolyte multilayered microcapsules reinforced smart coatings. J. Mater. Sci. 2019, 54, 12079-12094. [CrossRef]

18. Yang, J.; Lind, J.U.; Trogler, W.C. Synthesis of hollow silica and titania nanospheres. Chem. Mater. 2008, 20, 2875-2877. [CrossRef]

19. Ge, T.; Zhao, W.; Wu, X.; Wu, Y.; Shen, L.; Ci, X.; He, Y. Design alternate epoxy-reduced graphene oxide/epoxy-zinc multilayer coatings for achieving long-term corrosion resistance for Cu. Mater. Des. 2020, 186, 108299. [CrossRef]

20. Chenan, A.; Ramya, S.; George, R.P.; Kamachi Mudali, U. Hollow mesoporous zirconia nanocontainers for storing and controlled releasing of corrosion inhibitors. Ceram. Int. 2014, 40, 10457-10463. [CrossRef]

21. Borisova, D.; Möhwald, H.; Shchukin, D.G. Mesoporous silica nanoparticles for active corrosion protection. ACS Nano 2011, 5 , 1939-1946. [CrossRef]

22. Nawaz, M.; Shakoor, R.A.; Kahraman, R.; Montemor, M.F. Cerium oxide loaded with gum Arabic as environmentally friendly anti-corrosion additive for protection of coated steel. Mater. Des. 2020, 198, 109361. [CrossRef]

23. Li, Y.; Lin, X.; Wang, Y.; Luo, J.; Sun, W. Preparation and characterization of porous yttrium oxide powders with high specific surface area. J. Rare Earths 2006, 24, 34-38. [CrossRef]

24. Nagajyothi, P.C.; Pandurangan, M.; Veerappan, M.; Kim, D.H.; Sreekanth, T.V.M.; Shim, J. Green synthesis, characterization and anticancer activity of yttrium oxide nanoparticles. Mater. Lett. 2018, 216, 58-62. [CrossRef]

25. Qiao, J.; Zhang, M.; Zhang, X.; Zhang, K.; Zhang, S. Effect of yttrium oxide nanoparticles on corrosion resistance of chromium-free dacromet coating. Coat. Paint. Electroplat. 2016, 41, 178-181.

26. Yan, T.; Zhang, S.; Feng, L.; Qiang, Y.; Lu, L.; Fu, D.; Wen, Y.; Chen, J.; Li, W.; Tan, B. Investigation of imidazole derivatives as corrosion inhibitors of copper in sulfuric acid: Combination of experimental and theoretical researches. J. Taiwan Inst. Chem. Eng. 2020, 106, 118-129. [CrossRef]

27. Aghazadeh, M.; Ghaemi, M.; Nozad Golikand, A.; Yousefi, T.; Jangju, E. Yttrium Oxide Nanoparticles Prepared by Heat Treatment of Cathodically Grown Yttrium Hydroxide. ISRN Ceram. 2011, 2011, 1-6. [CrossRef]

28. Viveka, S.; Prabhuswamy, M.; Dinesha, D.; Lokanath, N.K.; Nagaraja, G.K. Synthesis, crystal structure, and characterization of new 2,4,5-triphenyl imidazole: 4,5-diphenyl-2-(3,4,5-trimethoxyphenyl)-1 h-imidazole. Mol. Cryst. Liq. Cryst. 2014, 588, 83-94. [CrossRef]

29. Trivedi, M.K.; Dahryn Trivedi, A.B.; Gunin Saikia, G.N. Physical and Structural Characterization of Biofield Treated Imidazole Derivatives. Nat. Prod. Chem. Res. 2015, 3, 1000187. [CrossRef]

30. Wong, C.P.; Miller, P.J. Vibrational spectroscopic studies of alane. J. Energ. Mater. 2005, 23, 169-181. [CrossRef] 
31. Khan, A.; Hassanein, A.; Habib, S.; Nawaz, M.; Shakoor, R.A.; Kahraman, R. Hybrid Halloysite Nanotubes as Smart Carriers for Corrosion Protection. ACS Appl. Mater. Interfaces 2020, 12, 37571-37584. [CrossRef]

32. Behzadnasab, M.; Mirabedini, S.M.; Kabiri, K.; Jamali, S. Corrosion performance of epoxy coatings containing silane treated ZrO2 nanoparticles on mild steel in 3.5\% NaCl solution. Corros. Sci. 2011, 53, 89-98. [CrossRef]

33. Taghavikish, M.; Dutta, N.K.; Choudhury, N.R. Emerging corrosion inhibitors for interfacial coating. Coatings 2017, 7, 217. [CrossRef]

34. Njoku, D.I.; Cui, M.; Xiao, H.; Shang, B.; Li, Y. Understanding the anticorrosive protective mechanisms of modified epoxy coatings with improved barrier, active and self-healing functionalities: EIS and spectroscopic techniques. Sci. Rep. 2017, 7, 1-15. [CrossRef]

35. Hosseini, M.; Aboutalebi, K. Electrochemical evaluation of corrosion protection performance of epoxy/polyaniline-imidazole modified ZnO nanocomposite coating on mild steel. Prog. Color Colorants Coat. 2017, 10, 181-192.

36. Otmacic Curkovic, H.; Stupnisek-Lisac, E.; Takenouti, H. The influence of $\mathrm{pH}$ value on the efficiency of imidazole based corrosion inhibitors of copper. Corros. Sci. 2010, 52, 398-405. [CrossRef]

37. Finšgar, M. The first X-ray photoelectron spectroscopy surface analysis of 4-methyl-2-phenyl-imidazole adsorbed on copper. Anal. Methods 2015, 7, 6496-6503. [CrossRef]

38. Barr, T.L.; Seal, S. Nature of the use of adventitious carbon as a binding energy standard. J. Vac. Sci. Technol. A Vac. Surf. Film. 1995, 13, 1239-1246. [CrossRef]

39. Safaei, Z.; Shiroudi, A.; Zahedi, E.; Sillanpää, M. Atmospheric oxidation reactions of imidazole initiated by hydroxyl radicals: Kinetics and mechanism of reactions and atmospheric implications. Phys. Chem. Chem. Phys. 2019, 21, 8445-8456. [CrossRef] [PubMed]

40. Hantsche, H. High resolution XPS of organic polymers, the scienta ESCA300 database. By G. Beamson and D. Briggs, Wiley, Chichester 1992, 295 pp., hardcover, £ 65.00, ISBN 0-471-93592-1. Adv. Mater. 1993, 5, 778. [CrossRef]

41. Miller, D.J.; Biesinger, M.C.; McIntyre, N.S. Interactions of CO2 and CO at fractional atmosphere pressures with iron and iron oxide surfaces: One possible mechanism for surface contamination? Surf. Interface Anal. 2002, 33, 299-305. [CrossRef]

42. Fraoua, K.; Aeiyach, S.; Aubard, J.; Delamar, M.; Lacaze, P.C.; Ferreira, C.A. XPS and SERS evidence for iron nitride species responsible for the strong adhesion of polypyrrole to iron or steel treated with nitric acid. J. Adhes. Sci. Technol. 1999, 13, 517-522. [CrossRef]

43. Gröning, P.; Nowak, S.; Schlapbach, L. Surface modifications of nitrogen-plasma-treated stainless steels. Appl. Surf. Sci. 1993, 64, 265-273. [CrossRef]

44. Nardeli, J.V.; Fugivara, C.S.; Taryba, M.; Montemor, M.F.; Benedetti, A.V. Self-healing ability based on hydrogen bonds in organic coatings for corrosion protection of AA1200. Corros. Sci. 2020, 177, 108984. [CrossRef]

45. Eduok, U.; Faye, O.; Szpunar, J. Corrosion inhibition of X70 sheets by a film-forming imidazole derivative at acidic pH. RSC Adv. 2016, 6, 108777-108790. [CrossRef]

46. Abdallah, M.; Megahed, H.E.; Sobhi, M. Ni ${ }^{2+}$ cation and imidazole as corrosion inhibitors for carbon steel in sulfuric acid solutions. Mon. Fur Chem. 2010, 141, 1287-1295. [CrossRef]

47. Singh, A.; Ansari, K.R.; Kumar, A.; Liu, W.; Songsong, C.; Lin, Y. Electrochemical, surface and quantum chemical studies of novel imidazole derivatives as corrosion inhibitors for J55 steel in sweet corrosive environment. J. Alloys Compd. 2017, 712, 121-133. [CrossRef]

48. Pire, M.; Lorthioir, C.; Oikonomou, E.K.; Norvez, S.; Iliopoulos, I.; Le Rossignol, B.; Leibler, L. Imidazole-accelerated crosslinking of epoxidized natural rubber by dicarboxylic acids: A mechanistic investigation using NMR spectroscopy. Polym. Chem. 2012, 3, 946-953. [CrossRef]

49. Shao, L.; Sang, Y.; Huang, J. Imidazole-based hyper-cross-linked polymers derived porous carbons for $\mathrm{CO}_{2}$ capture. Microporous Mesoporous Mater. 2019, 275, 131-138. [CrossRef]

50. Mendes, J.O.; Da Silva, E.C.; Rocha, A.B. On the nature of inhibition performance of imidazole on iron surface. Corros. Sci. 2012, 57, 254-259. [CrossRef] 